\title{
A COMPARISON OF CROSS-STREAM VELOCITIES AND GULF STREAM TRANSLATIONS UTILIZING IN-SITU \\ AND REMOTELY-SENSED DATA
}

by

CLARR BRUCE FREISE

B.S. Oceanography

United States Naval Academy

(1986)

\author{
Submitted to the \\ Massachusetts Institute of Technology/ \\ Woods Hole Oceanographic Institution \\ Joint Program in Oceanography and \\ Oceanographic Engineering \\ in Partial Fulfillment of the Requirements \\ of the Degree of \\ Master of Science \\ at the \\ Massachusetts Institute of Technology \\ and the \\ Woods Hole Oceanographic Institution
}

September, 1988

(C) Clark B. Freise, 1988

The author hereby grants to MIT, WHOI, and the U.S.

Government permission to reproduce and to distribute copies

of this thesis document in whole or in part.

Signature of Author

Joint Program in Oceanography and Oceanographic Engineering Massachusetts Institute of Technology/

Woods Hole Oceanographic Institution

Certified by

Dr. Wicholas P. Fofonoff Senior scientist, W.H.O.I.

Accepted by

Professor Carl Wunsch, Chairman Joint Committee for Physical Oceanography 
Abstract:

In previous Gulf Stream work (Hall'and Bryden, 1985, Hall, 1985, 1986A, 1986B), a decomposition of multiple depth current records was developed which produced along- and cross-stream components. The cross-stream component was found to occasionally match lateral displacements of the Stream, as determined by temperature changes measured at the current meters.

This study determined where within the meander pattern of the Gulf stream the cross-stream velocity calculated from current meters at depth correctly predicted translations of the Gulf stream as measured by satellite data. Additionally, the effects of recently quantified cross-stream velocities associated with the curvature of Gulf stream meanders were analyzed. 


\section{Acknowledgements:}

Funds for the computer system used and the data sets contained within this work were provided by ONR contracts N00014-86-K-0751 and N00014-87-K-0007.

I am indebted to the United states Navy for giving me the opportunity to pursue my graduate studies at MIT and WHOI.

I am additionally indebted to my advisor, Nick Fofonoff, my fellow Joint Program students, various members of the WHOI staff, my family, and my fiancee Amy for their support and assistance during my research. 
Table of Contents:

Introduction/History $\quad \ldots \ldots \ldots \ldots \ldots \ldots \ldots$

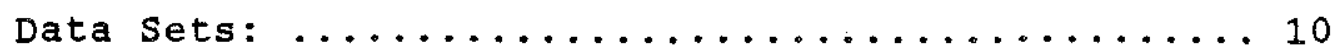

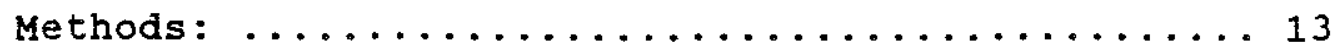

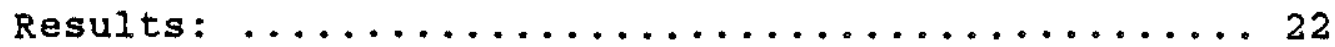

Recent Observations (RAFOS Floats): ......... 25

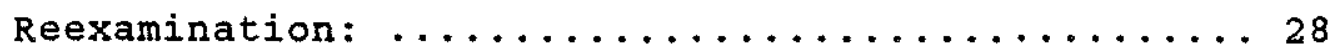

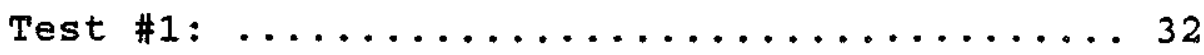

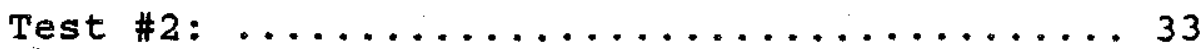

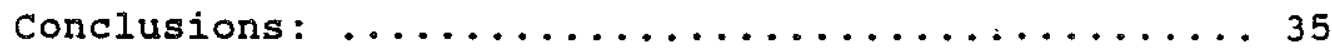

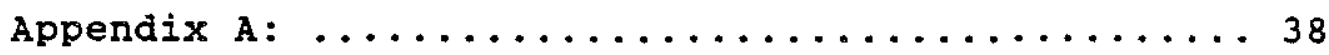

Appendix B : $\ldots \ldots \ldots \ldots \ldots \ldots \ldots \ldots \ldots \ldots \ldots \ldots$

Appendix $c: \ldots \ldots \ldots \ldots \ldots \ldots \ldots \ldots \ldots \ldots \ldots \ldots \ldots \ldots$

Bibliography: $\ldots \ldots \ldots \ldots \ldots \ldots \ldots \ldots \ldots \ldots$ 
Table of Contents:

Introduction $/$ History $: \ldots \ldots \ldots \ldots \ldots \ldots$

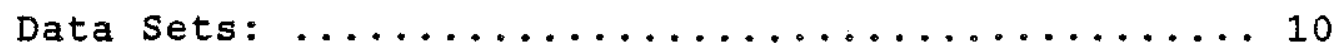

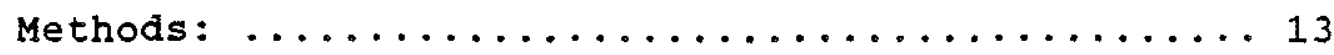

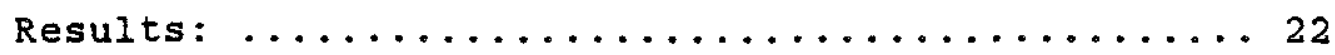

Recent Observations (RAFOS Floats): .......... 25

Reexamination: $\ldots \ldots \ldots \ldots \ldots \ldots \ldots \ldots \ldots \ldots$

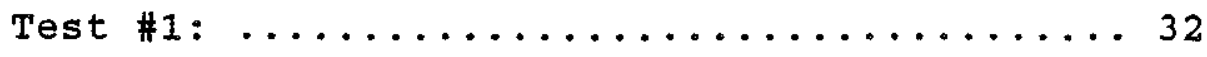

Test \#2: $\ldots \ldots \ldots \ldots \ldots \ldots \ldots \ldots \ldots \ldots \ldots \ldots \ldots$

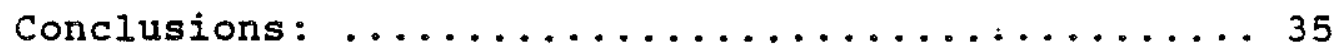

Appendix A: $\ldots \ldots \ldots \ldots \ldots \ldots \ldots \ldots \ldots \ldots \ldots$

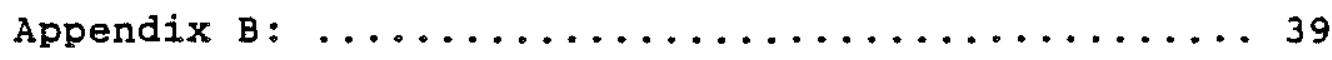

Appendix $c: \ldots \ldots \ldots \ldots \ldots \ldots \ldots \ldots \ldots \ldots \ldots \ldots$

Bibliography: $\ldots \ldots \ldots \ldots \ldots \ldots \ldots \ldots \ldots \ldots \ldots$ 


\section{List of Figures:}

Fig. 1: Hall and Bryden Gulf stream Cross-Section ...... 7

Fig. 2: Cross-Section Model of Velocities and Density ... 9

Fig. 3: Infra-Red Image of Gulf stream Area ......... 14

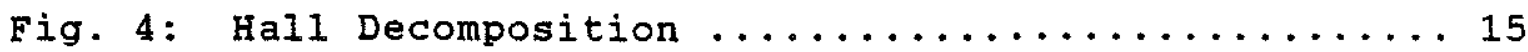

Fig. 5: Infra-Red Image with North Wall Added ........ 18

Fig. 6: Test Plot for Translational Hypothesis ....... 20

Fig. 7: Locations of Moorings Used in study .........24

Fig. 8: Temperature vs. Pressure Contours .......... 26

Fig. 9: Plot Used in Determination of Locations within the Gulf Stream the Hypothesis Worked/Failed ... 29

Fig. 10: Sectioning used for Comparison of Translational

Hypothesis and RAFOS Data ............. 31

Fig. 11: Plot with Barotropic RAFOS Determined Velocity

Removed from Current Record ............. 34

Fig. 12: Cross-Sections of Velocity and Density Fields

Including RAFOS Determined Velocity ........ 36

Fig. C1: Plot Showing scoring Method used in Study .....4 41

Fig. C2, C3, C4: Additional Example Plots (Scored) . 43,44,45 


\section{Introduction/History:}

A major area of research in physical oceanography has been the study of the kinematics and dynamics of western boundary currents, in particular the Gulf stream (Fofonoff, 1981). Much of the past interest has been focused on describing the "cause" of the stream itself. Theories justifying its existence have ranged from the westward motions of the heavenly bodies to rivers emptying into the Gulf of Mexico (both wrong) (history from stommel, 1958). More interest is now being applied to the determination of the along- and cross-stream structure and dynamical balances involved within the stream, especially in the vicinity of highly energetic meanders, rings, and eddies.

Hall and Bryden (1985; Hall, 1985, 1986A, B) approached this problem in a unique fashion. Using current records from a single mooring, they constructed a mean time invariant lowest order velocity cross-section for the Gulf stream (Fig. 1). They proposed that this cross-section (termed a canonical structure) was locally constant in the along-stream direction with only small deviations in the area tested (West of the New England Seamounts), these deviations being important to the local dynamics of the stream. As part of the construction of the cross-section, Hall and Bryden decomposed the current record into two components: one aligned with the direction of the shear (vertical derivative of horizontal velocity), termed the along-stream component, 


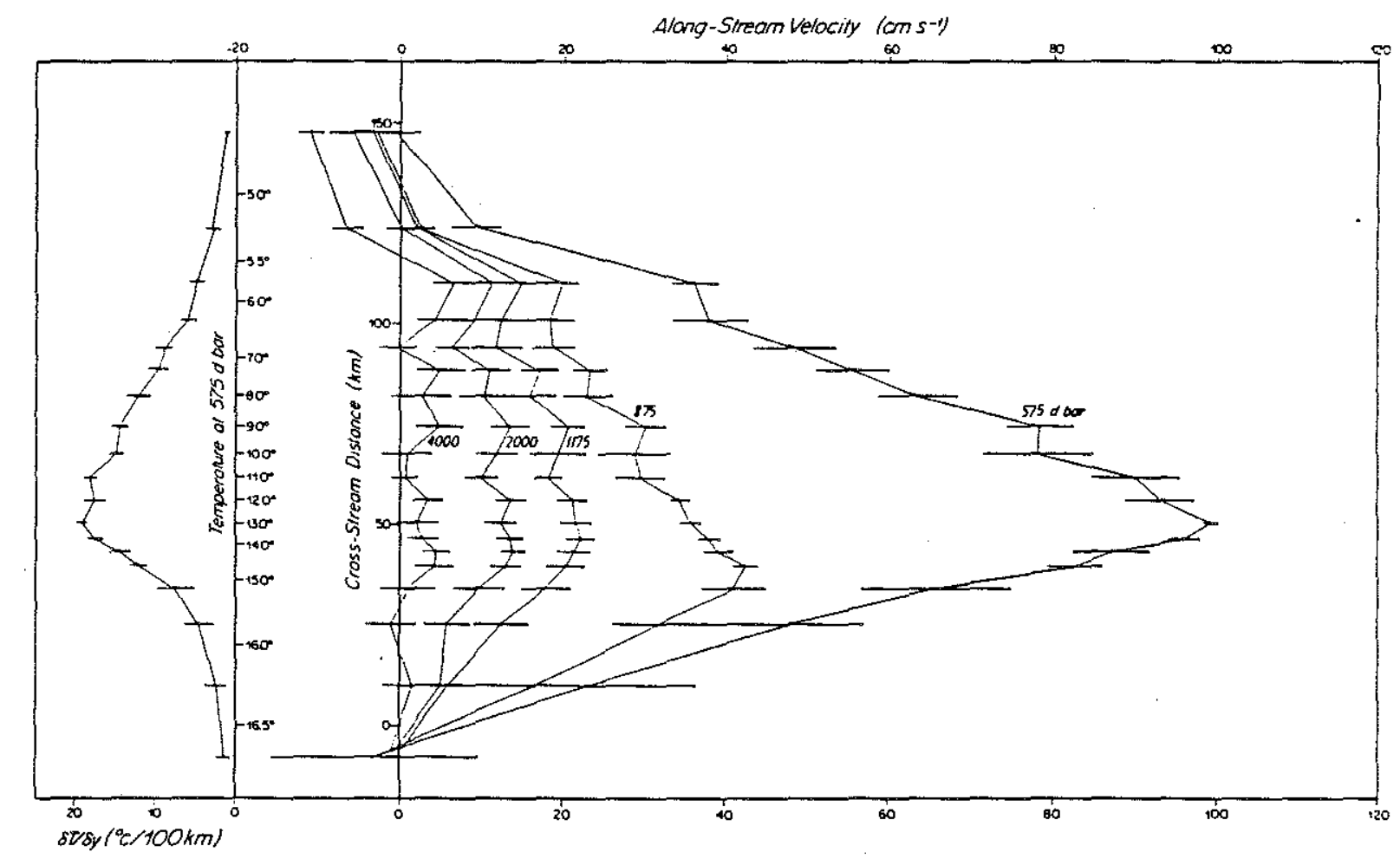

Average horfzontal and vertfeal profile of velocity in Guif streara, from year-iong time sertes at $58^{\circ} \mathrm{W}$. Detalls of how proftie was obtained in Hall and Bryden (1985).

\section{Figure 1}

Hall and Bryden Cross-Section of the Gulf stream

Velocity.

(Reprinted with permission. Hal1, 1986) 
and the remainder that is perpendicular to the shear (the cross-stream component). An interesting discovery evolved from this decomposition: while the along-stream component was baroclinic, the cross-stream component was highly barotropic (not a function of depth). The first result is expected from the historical observation that the Gulf stream is a surface intensified jet with a strong signature in the density field. However, the second result is slightly surprising and has some possibly valuable uses. If the Gulf stream does have fixed cross-sectional structure, the cross-stream component can be interpreted as a velocity imparted onto the meters by the translation of the stream across the mooring (Fig. 2). This translational hypothesis was found to correctly determine the Gulf streams translations, as shown in temperature changes, by Hall (1985, 1986A, B) in certain cases. However, Hall also showed that the hypothesis also incorrectly determined the sign of the change in temperature in cases associated with high curvature of the Gulf stream. Hall (1986B) determined that the likely explanation of this apparent paradox was that vertical velocities caused by stretching and compressing of the water column induce cross-stream velocities as water parcels seek to remain on the strongly sloping isotherms in the stream. The changing of the temperature field could be caused by the Gulf stream balancing the centrifugal forces associated with the high curvature found in Gulf stream meanders. 


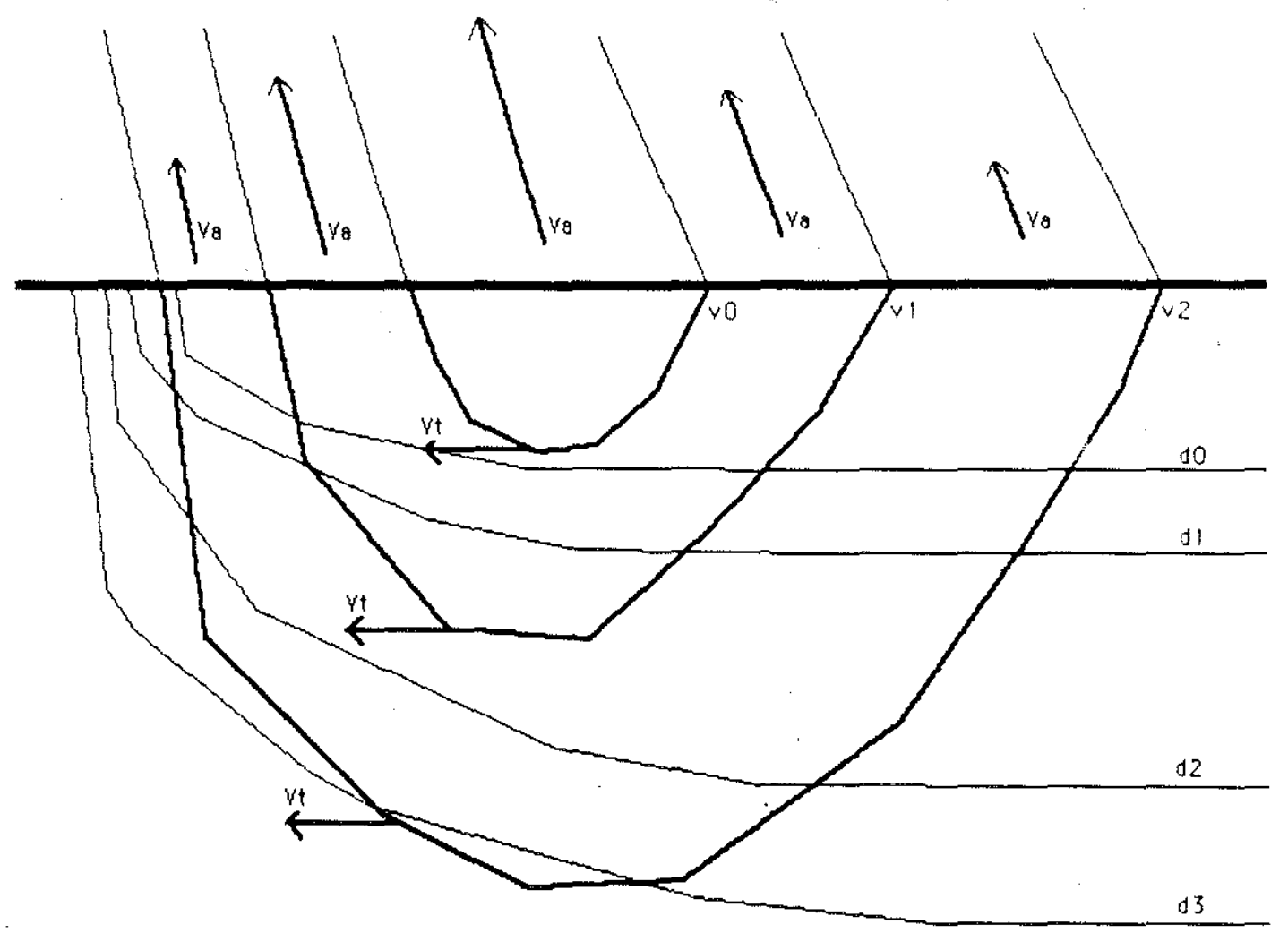

Figure 2

Cross-Section Showing Models of Velocity $\left(V_{x}\right)$ and

Density $\left(d_{x}\right)$ Fields for Gulf stream.

$V_{a x}=$ along-stream velocity for level $x$

$v t_{x}=$ translational velocity for level $x$

$\mathrm{Va}_{0}>\mathrm{Va}_{1}>\mathrm{Va}_{2}$

$V t_{0}=V t_{1}=V t_{2}$ 
The purpose of this study is to determine if the cross-stream velocities observed by Hall at mid-thermocline depths can be extrapolated to the surface where they might be detected in thermal front translations observed in satelitite data. That is, can the translations of the thermal front, as determined by using sateliites, be predicted/explained by the current measurements taken at greater depths within the Gulf Stream? If there is a direct connection between the two levels, it could greatly simplify certain tasks involved with the study of the Gulf stream. In this study, translations observed from satellite measurements of the thermal front are compared with translations predicted from in-situ current meter measurements (using the decomposition developed by Ha11). Also, recent float data (Bower, 1988) will be examined to determine the consistency of the observed and calculated translations with lagrangian measurements of along- and cross-stream flow.

\section{Data Sets:}

In the Hall papers data from one mooring was used. This was in large part due to the mooring being a proof of concept experiment to show that it was possible to moor a series of meters in the stream for long time periods lorder of a year). Because only a single mooring was available, translations of the Gulf stream were determined from mean temperature cross-sections and changes in temperature 
measured at the mooring.

It would be beneficial to have an array with a greater number of moorings to determine where within the stream structure the inferred translational velocities are actually reflected in the displacements of the Stream's thermal front. In 1983-1984 an array of six moorings was set by Ross Hendry of the Bedford Institute of Oceanography (five moorings returned data)(technical report is listed under Atlantic Oceanography Laboratory Cruise Report 84-012). The array was part of the Gulf stream statistical and Mapping Experiment (GSSME) (Hogg et.a1., 1986). The larger number of moorings allows for a comparison of multiple measured cross-stream velocities with observed displacements of the Gulf stream.

A listing of all mooring data used in this study is contained in Appendix A. The GSSME array consisted of moorings containing 4 Aanderaa current meters each (one mooring RH560X returned data for only 3 meters) set at various depths located in the mean path of the Gulf stream in the area of 39.5 North 59 West. This area is considerably east of the GUSTO (GUIf STream Observations) mooring used by Hall. The use of a canonical description of the Gulf stream east of the New England seamounts has only recently been attempted (Hendry, 1988).

The data used for determining the translational velocities for this study were calculated using all the data 
returned from the GSSME moorings in 1983.

The data sets available for locating and measuring the surface motions of the Gulf stream are limited. The only available sets that contain sufficient temporal and spatial coverage for a proper check of the hypothesis are remotely sensed data sets. Available remote data sets that are capable of imaging the Gulf stream include infra-red, altimeter, visual photography, microwave radiometry, and synthetic-aperture radar. The one most commonly used for observing the Gulf stream, however, is satellite infra-red (IR) imagery. This is available from a large number of satellites (e.g. Tiros $N$ and NOAA 6-10 (Cornillon et.al., 1987) (nd is archived at various academic as well as commercial locations. While the IR images are numerous and present an aesthetically pleasing view of the Gulf stream, they are very difficult to use in determining the exact location of the thermal front since each image is usually degraded by cloud cover. Additionally, the necessity of remapping the image to ground coordinates is very difficult and time consuming. These problems with the IR imagery were circumvented in this study by use of the "North Wall" data prepared by the University of Rhode Island (Cornilion et. al., 1987). This has been used in the past for studies of the Gulf stream and in particular for measuring meandering (Cornilion, 1986).

The North Wall data used in this study was developed by 
Craig Gilman. To determine the North Wall, a two-day composite image is created to reduce cloud cover. All of the passes during the two day period are mapped onto the same geographical grid allowing for multiple data points at most pixels (specific latitude/longitude coordinates). From all of the passes contained in the two day period the warmest value is chosen at each pixel. Since cloud temperatures are much colder than the ocean, this effectively eliminates the clouds, unless there was continuous cover during the time period (this is not uncommon in the array area). From the two day composite, a North Wall is subjectively drawn. This method was chosen as its performance was found to be better than objective mapping (Cornillon et.al.,1987).

The North Wall was chosen since it is the most easily delineated feature in IR images of the Gulf stream region. This is due to the sharp thermal gradient caused by the warmer waters of the Gulf stream coming into contact with the colder slope water (Fig. 3).

\section{Methods:}

The decomposition of the current records was done using the same methods as Hall $(1985,1986 \mathrm{~A}, \mathrm{~B})$. The velocity record from a lower instrument is subtracted from a shallow record to determine the shear direction (see Fig. 4 and Eq. 1a). 


\section{4}

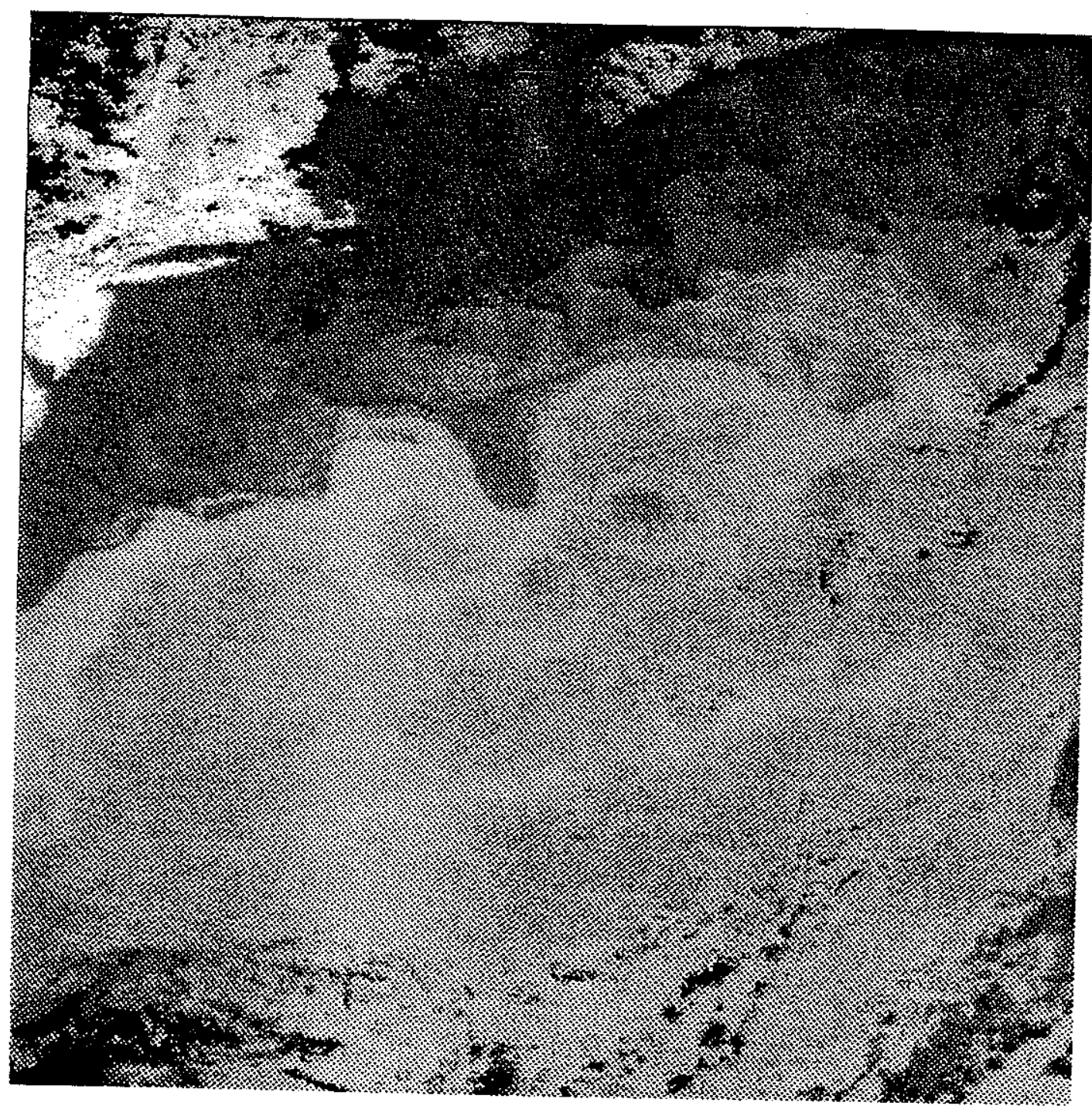

Figure 3

Infra-Red Image of Gulf stream Area Taken From NOAA-9 Satellite. 


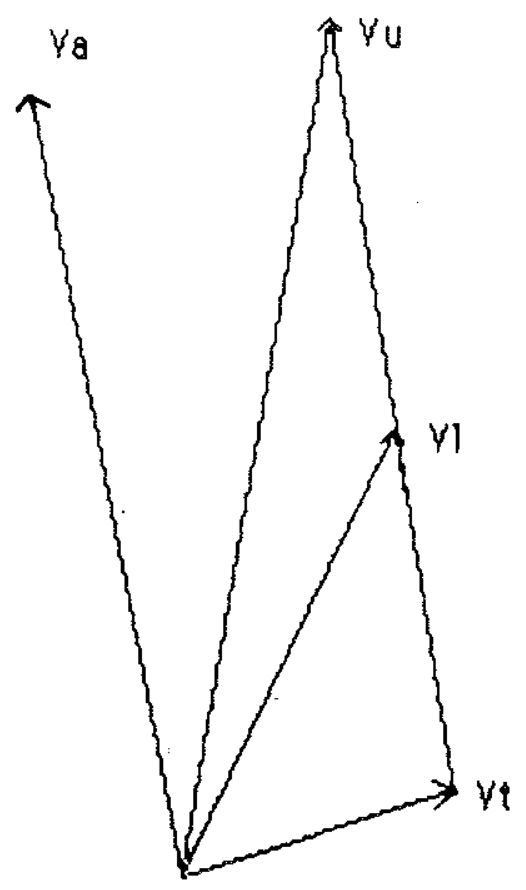

Figure 4

Hal1 Decomposition.

With: Vu = Upper Layer Velocity

$\mathrm{VI}=$ Lower Layer Velocity

$\mathrm{Va}=$ Velocity in Along-stream Direction

$\mathrm{Vt}=$ Translational Velocity 


$$
\begin{aligned}
v_{s}= & v_{u}-v_{l} \\
\text { with: } & v_{u}=\text { upper velocity } \\
v_{l} & =\text { lower velocity } \\
v_{s} & =\text { velocity in shear direction }
\end{aligned}
$$

The vector projection of the upper velocity in the shear direction is then determined (Eq. 1b).

$$
V_{A}=\left(V_{u}\left|\frac{V_{B}}{\left|V_{s}\right|}\right| \frac{V_{s}}{V_{s}} \mid\right.
$$

Eq. 1b (Wylie, 1982)

with: $\left|V_{B}\right|=$ magnitude of $V_{B}$

$$
V_{A}=\text { along-stream velocity }
$$

The translational (cross-stream) velocity is then determined by subtracting the projection of the upper velocity from the original upper velocity (Eq. 1C).

$$
\mathrm{V}_{\mathrm{u}}-\mathrm{V}_{\mathrm{A}}=\mathrm{V}_{\mathrm{t}} \quad \mathrm{Eq} \cdot 1 \mathrm{C}
$$

with: $V_{t}=$ translational velocity

For this study the two upper current meters on each

mooring were used to determine the translational velocities as close as possible to the level in which the actual translations would be measured (the thermal layer). In the case of this study the average depths of the meters used were: $472 \mathrm{~m}$. for the upper meter and $1003 \mathrm{~m}$. for the lower meter. This choice also minimizes the chance of including any interfering signal from topographic rossby waves, which are bottom intensified. Currents associated with topographic rossby waves have been seen in some drifter data and past current mooring measurements (Bower, personal communications, 
Bower, 1988, Johns et. al., 1985). Use of the uppermost meters is a slight departure from the Hall study when the $2000 \mathrm{~m}$. meter on the mooring was used for the lower level velocity in the calculations. The $4000 \mathrm{~m}$. current meter was eliminated by Hall due to flow reversals measured at that depth, and to also reduce the aforementioned wave influence. The first steps taken were to determine the accuracy of the North Wall data in the vicinity of the array. The procedure consisted of creating a series of images which contained nearly instantaneous images of the Gulf stream region, using remapped IR data, and then overlaying the North Wall data from the same time period (Fig. 5). The contrast of the IR images was Iinearly stretched to improve the identification of the thermal front in the images using SDPS, the Woods Hole Oceanographic Institution's Satelitte Data Processing system, a satellite image processing and display program. All computer programs used in this project are listed and described in Appendix B. These images were then checked to determine the level of accuracy in the North Wall data.

The North Wall data were found to be accurate in locating the general position and orientation of the Gulf stream. However, since the North Wall data is a composite taken from multiple images the match is not exact. The errors found were on the order of 0.1 degree of latitude 


\section{8}

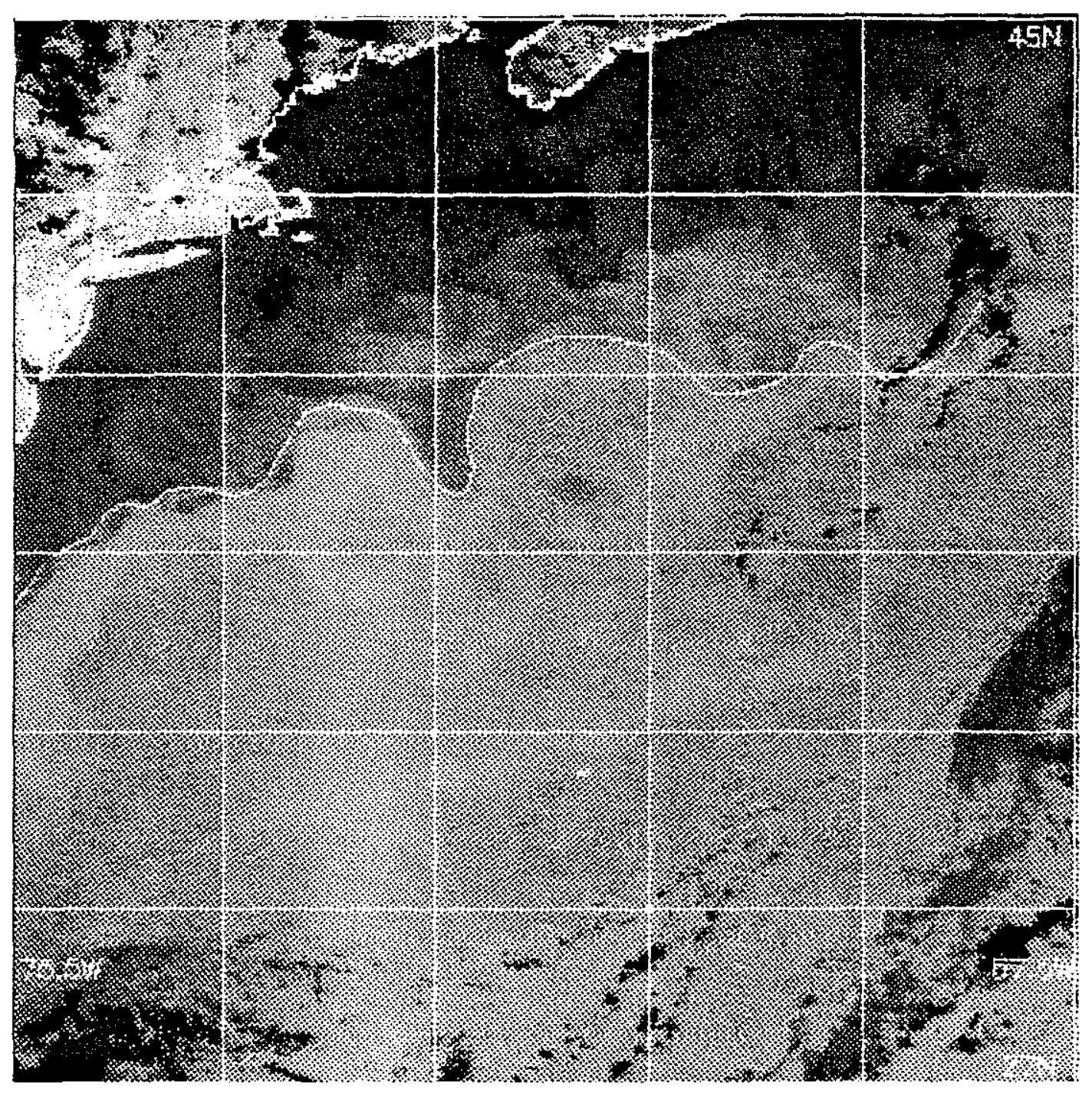

\section{Figure 5}

Infra-Red Image with North Wall Data Superimposed. 
(approximately $10 \mathrm{~km}$.). This matches the findings of Cornilion et. al. (1987), who found errors to be less than 15 $\mathrm{km}$. using an inverted echo sounder to measure the actual position of the Gulf stream. Certain events exhibited errors in excess of this level. One particular cause of error was found in the vicinity of cold core ring formation and interaction. In certain cases it was noted that where the North Wall data for day $x$ would delineate a path along a developing ring, the data for day $x+2$ would only show a straight (or very slightly curved) line through the region. This is, however, easy to notice in a time series of images and was eliminated from the data sets by removing the days in which the straight line was found.

Once the accuracy of the North Wall data had been determined, the next step was to combine the in-situ measurements with the remotely sensed data to determine if the translations predicted in the current record could be observed in the North Wall data. The method used was to plot (Fig. 6) two sequential maps of the North Wall position, the location of the actual mooring (marked $x$ ), and the location to which a water parcel originally located at the mooring would be translated if it had been displaced according to the translational velocity calculated at the mooring (marked $R$ ). This was used as an indicator of the direction in which the North Wall data should have progressed according to the hypothesis. These plots were made using PLOTXY, a public 
N. Wall IR for Days 133135

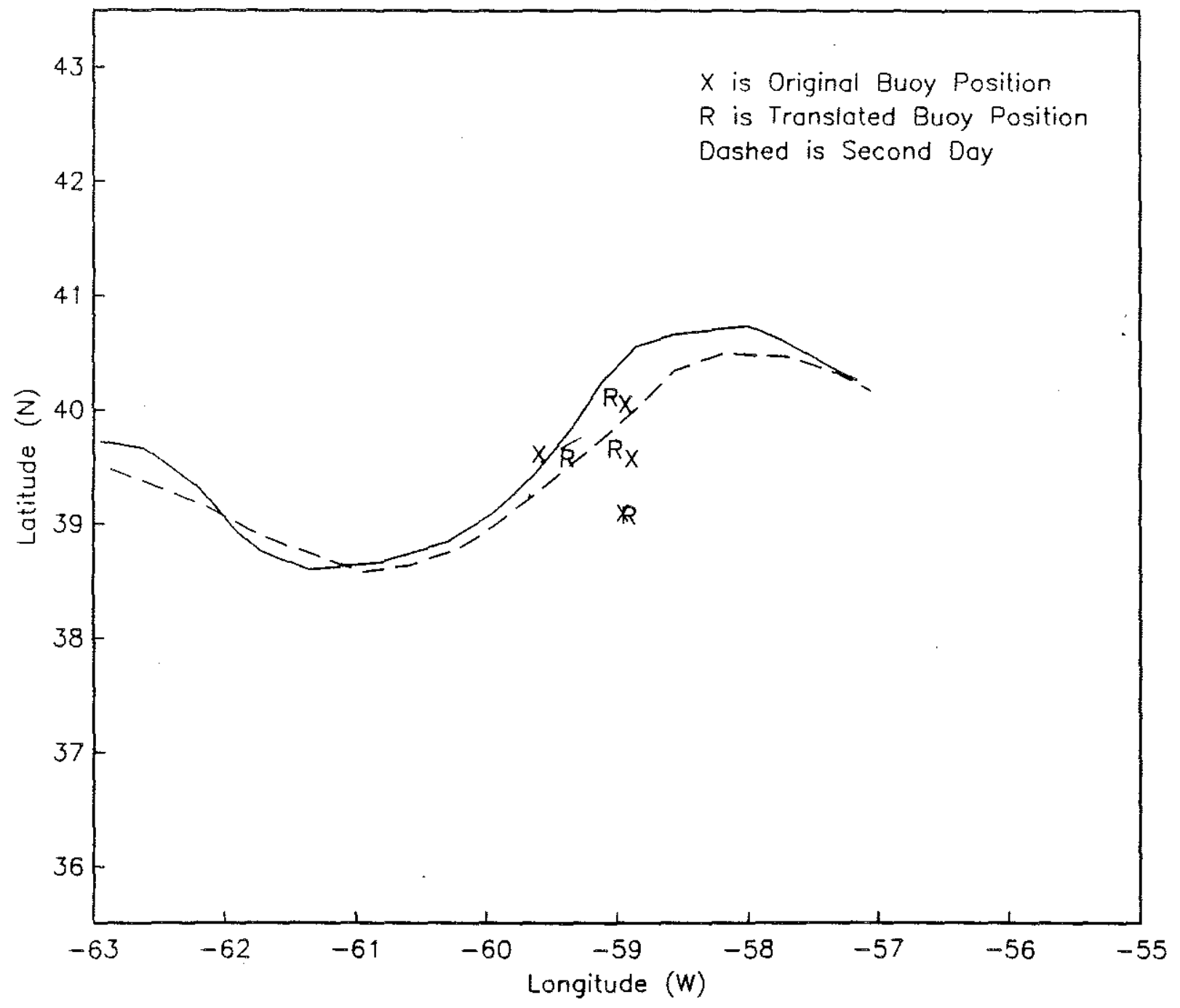

Figure 6

Test Plot for Test of Translational Hypothesis.

$\mathrm{x}$ marks mooring position

$R$ denotes translation predicted by measurements at mooring Solid line denotes North wall data for day $x$ Dashed line denotes North Wall data for day $x+2$ 
domain plotting program. The plots were done in boxes with the $x-y$ coordinates adjusted to compensate for the differences in distance associated with a degree of latitude and a degree of longitude at the center latitude for the array .

The translations were compared by determining the point in the day $x$ North Wall data nearest the mooring location. Then, using the translation indicated by the difference in location of the " $R$ " and its corresponding mooring (" $X$ "), it was determined if the day $x+2$ North wall data went through the indicated location (a more detailed description of the scoring system used and additional examples are included in Appendix C). The scoring method used was fairly simple. Data were not used if the mooring was located shoreward of the North Wall position on either of the dates used. This was done to eliminate any anomalous results that may have been caused by one or more of the meters being outside of the stream and measuring a current not entirely associated with the stream. Currents opposite in direction to the Gulf stream have been measured in the region just outside the North Wall using neutrally buoyant floats (Bower, 1988). Additionally, many plots had to be removed from the analysis due to dropouts of the North Wall data within the plots. Most of the dropouts are associated with persistent cloud cover that was not removed by the two day composite methods used in creating the North Wall data. This greatly decreases 
the amount of data since even with the two day averaging there is still a great deal of imagery with persistent cloud coverage.

\section{Results:}

Using the methods described above for the 5 moorings in the GSSME array in 1983, it is found that only 96 data points are available (32 plots with sufficient IR coverage). of these, only 56 points are "below" (i.e. South of) the North Wall data for both of the days in the plot. The results of this examination of the data are as follows:

Support the hypothesis: 15

Dispute the hypothesis: 41

Another useful way to look at the results is to examine the percent of the data points that support the hypothesis (support/(support+dispute) ) which is $26.8 \%$ for this example. This would tend to cause one to disbelieve the hypothesis.

To determine if the data may be simply insufficient to truly check the hypothesis, a similar test was done for two single mooring deployments, the GUSTO and ABC arrays, for 1983. The ABCE (AByssal Circulation Experiment) experiment actually involved multiple moorings, but only one mooring ( $A B C E 780 X)$ was used for this study due to the availability of the data and time constraints. The results from those tests are as follows: 
ABCE array $(39.6 \mathrm{~N}$ 60W):

$\begin{array}{ll}\begin{array}{ll}\text { Support the hypothesis: } \\ \text { Dispute the hypothesis: }\end{array} & 4 \\ \text { Percent that support: } & 30.7 \% \\ \text { Guspo array }(37.5 \mathrm{~N} \text { 60W }): & \\ \text { Support the hypothesis: } & 5 \\ \text { Dispute the hypothesis: } & 27 \\ \text { Percent that support: } & 15.6 \%\end{array}$

That gives a composite of only $23.8 \%$ support for the hypothesis. It was noted however, that the accuracy of the North Wall data did not appear to be as high in the region of the GUSTO mooring (see Fig. 7 for locations). This is possibly due in part to distortions caused by the satellite imagery being remapped to a central area within the satelite pass. The errors associated with infra-red satellite imagery increase away from the location at which the satelite pass is centered.

An additional check can be made by looking at the translations in the thermal structure of the stream as measured by the array. On each of the current meters there were also temperature and pressure sensors. Using the eleven sensors that returned data a cross section can be made. This was done for a series of dates (days 195 through 199) that supported the hypothesis, using the North Wall data, to determine if the translations could also be seen at depth. The process used was to input the latitude, pressure and temperature into Z-GRID (a public domain gridding program), plot the output using CONTOUR (again a common public domain 


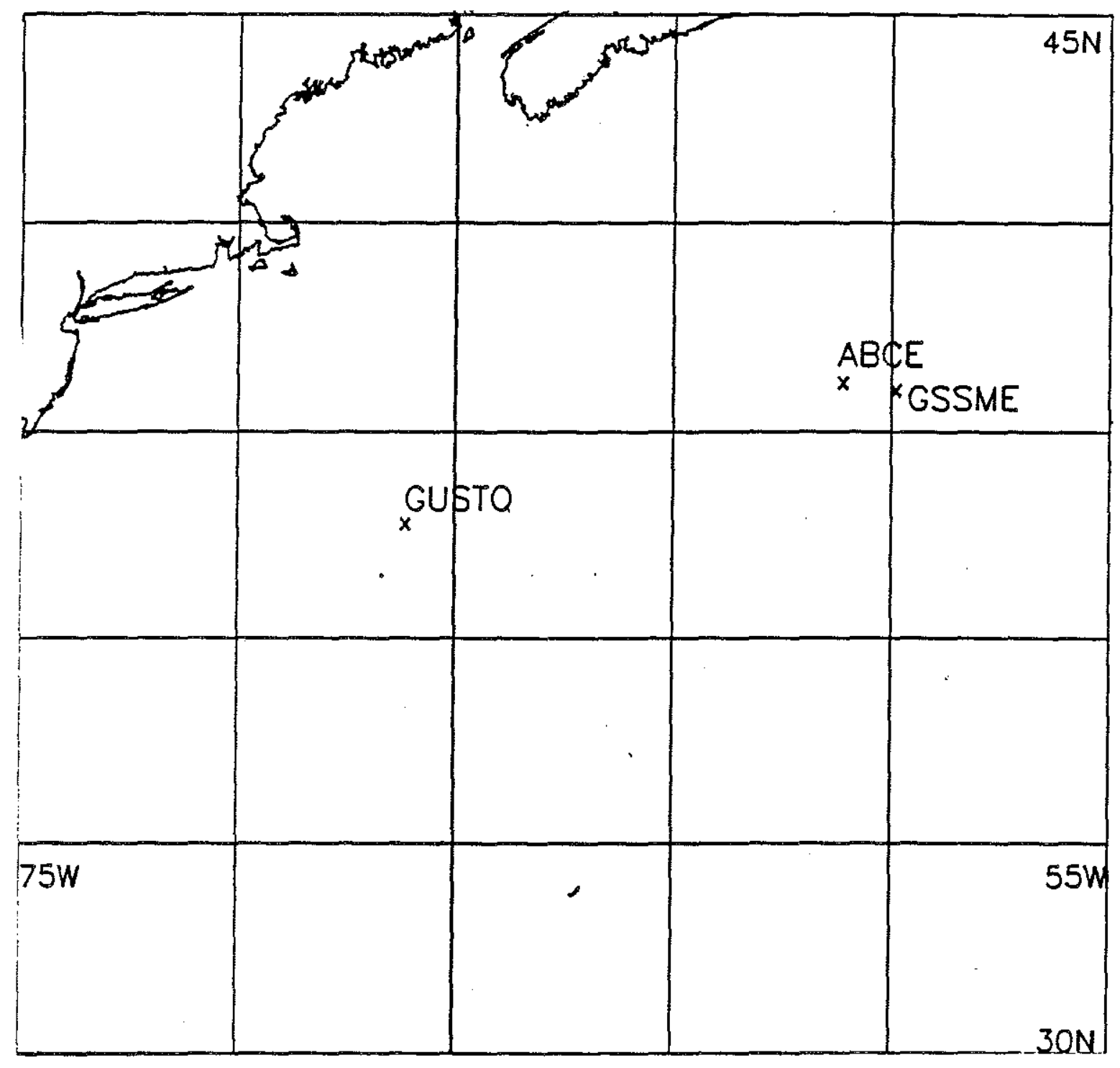

Figure 7

Locations of Moorings Used in Testing

Translational Hypothesis.

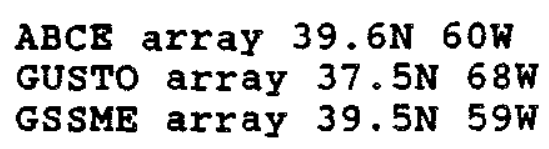


program), and then translate the latitude coordinate to see if the hypothesis correctly predicted the translation. Unfortunately, eleven points is not sufficient to get an accurate cross section of the Gulf stream thermal structure. Certain obvious distortions are seen in the plots (Fig. 8) (such as temperature minima at $2500 \mathrm{~m}$. ), but there is a trend present. The translations predicted by the hypothesis are generally in the same direction as the displacements observed in the thermal structure by the sensors. The match-up is not exact, but due to the aforementioned distortions that is expected. Therefore, it is concluded that, to within the accuracy of the data available, the thermal structure is displaced in the direction predicted by the translational hypothesis when the hypothesis correctly predicts the translations of the thermal front. However, it may also be concluded that it is unlikely the thermal displacements would be correctly predicted when the hypothesis fails to predict the surface translations, though this was not tested.

\section{Recent Observations (RAFOS Floats):}

Recent observations (Bower, 1988) made with RAFOS floats may explain a large portion of the errors found using only the translational hypothesis to determine the translational velocities. The RAFOs float is a Lagrangian tracer similar to the more common SOFAR float (note the name similarityl.: The major differences are in the data 


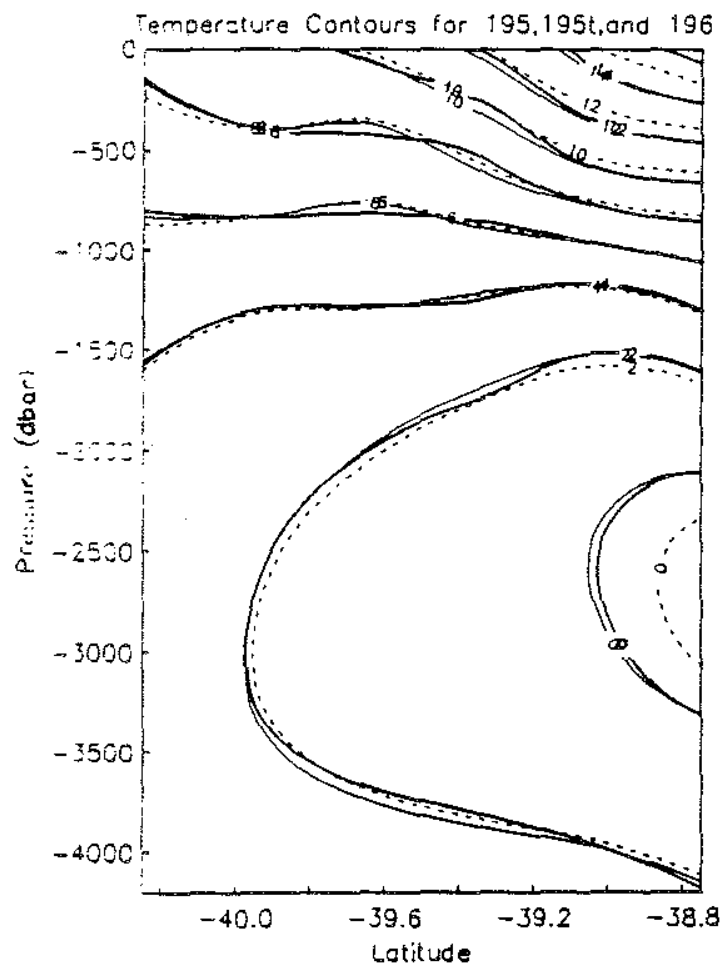

.95 light, 195t dork, 196 dashed

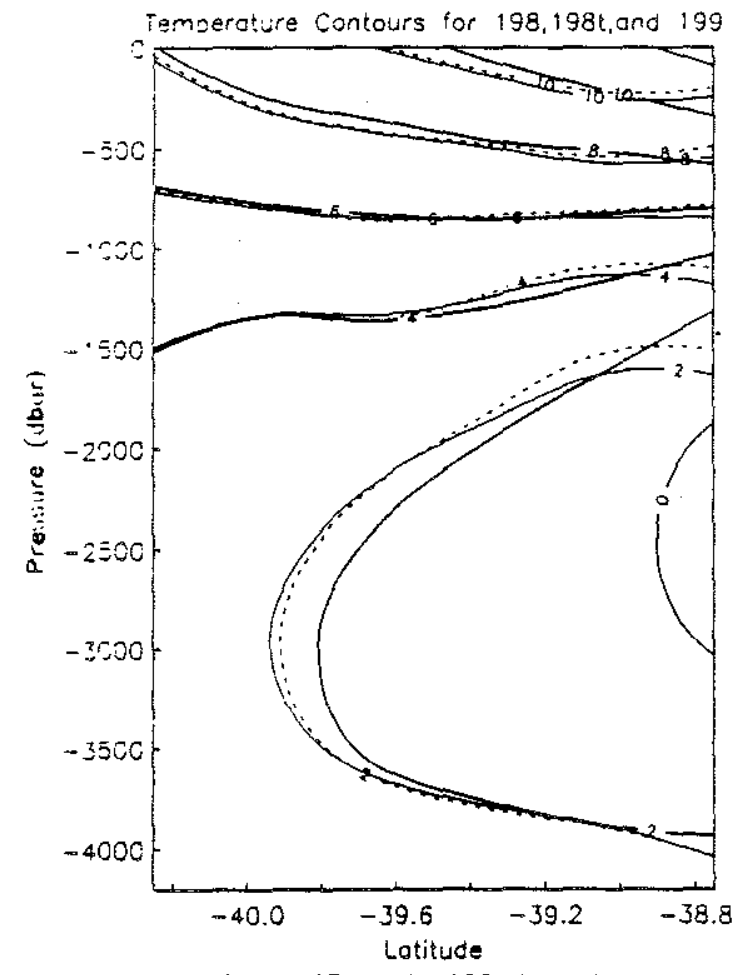

198 light, $198 \mathrm{t}$ Jark, 199 Joshed

\section{Figure 8}

Plots of Temperature vs. Pressure Contours

for Days $195-6$ and $198-9$

Day 19X Contours - Light Lines

Day 19xt (Translated) Contours - Dark Lines

Day 19X+1 Contours - Dashed Lines 
transmission/collection systems (unimportant for this study) and in the ballasting systems. The SOFAR float is ballasted to remain at a constant pressure surface (depth), while the RAFOS float is ballasted with a spring backed piston to remain on a constant density surface (Bower, 1988).

In the RAFOS data a cross-stream velocity was found in the vicinity of meanders in the Gulf stream. The method used by Bower to determine the magnitude of the cross-stream velocities was to use a time mean hydrographic cross section prepared in the PEGASUS (Halkin and Rossby, 1985) experiment, and by looking at the changes in pressure measured by the float as it followed the isopyncnals, determine a mean velocity. The velocities found were highly correlated with the location of the float within the meander pattern. The floats tended to flow upward and to the "north" (assuming a purely eastward flowing section) as the float neared a crest in the meander and opposite as it neared a trough in the meander. The maximum velocities were found where the curvature of the stream reached zero, i.e. as the curvature was changing sign. The velocities were on the order of 10 $\mathrm{cm} / \mathrm{s}$ in these "straight" sections and dropped to approximately zero at the peaks. These results are consistent with qualitative observations made by Hall (1986B) in explaining cases observed in the GusTo work in which the translational hypothesis failed to predict the proper changes in the temperature field. 
This cross-stream velocity would appear to be contained within the solid canonical stream envisioned before since many of the floats followed the stream from beginning to end without being ejected from the stream.

To determine if the decomposition proposed by Hall shows a translational cross-stream component that is being overshadowed by this internal cross-stream flow, a reexamination of the data must be done.

\section{Reexamination:}

The plots in which points had been scored as supporting or disputing the hypothesis were reexamined to determine in which portions of the meander pattern the hypothesis had failed or worked most often. The method used was to draw an approximate "South Wall" onto the plots using the day $x$ North Wall data and an $80 \mathrm{~km}$. cross section (Fig. 9). The $80 \mathrm{~km}$. cross section was chosen after examining various cruise data (Endeavor cruise 1988, unpublished, R/V Hakon Mosby, 1986) and consultation with investigators (Fofonoff and Hogg, personal communications). The stream was then dissected into sections estimating the quarters of the stream between a crest and a trough. On some plots this was not possible since there was not an obvious trough and crest surrounding the mooring in question. A total of 26 points were found to be surrounded by a noticeable trough and crest within the plots. Four additional points were found to be obviously in certain portions of the meander pattern. From these points 
N. Wall IR for Days $163 \quad 165$

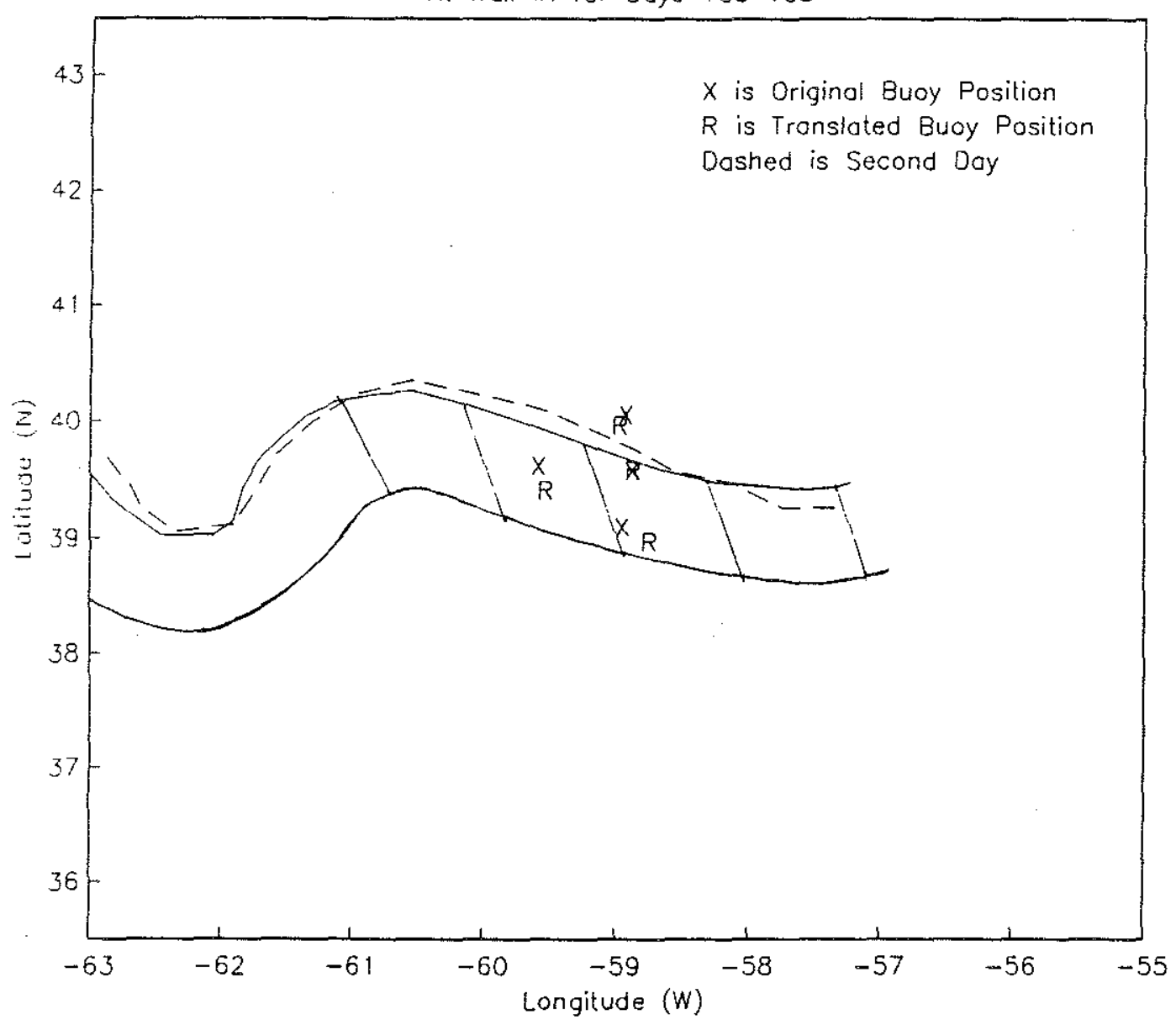

Figure 9

Plot used for Determining Positions within the

Meander Pattern in Which the Hypothesis Failed

to Predict the Translations. 
the following results are found (see Fig. 10 for description of locations used):

Crest/Trough (quarters on each side):

Support hypothesis: 9

Dispute hypothesis: 6

Ratio of support: 0.600

"Straight" sections:

Support hypothesis: 2

Dispute hypothesis: 13

Ratio of support: 0.133

The substantially different ratios for the two cases suggest that the translational hypothesis does apply in certain regions within the meander pattern.

The RAFOS data, however, has certain difficulties associated with it. There is a question (Hall, 1986B; Fofonoff, personal communications) as to whether the changes in depth measured by the float could be associated with a shallowing or deepening of the Gulf stream in the vicinity of a peak. This could be caused by the stream trying to offset the centrifugal forces associated with the meander. Additionally, the RAFOS floats were only used in the upper $400-700 \mathrm{~m}$. of the stream to increase the retention of the floats in the stream. Since the translational hypothesis applies to the differences in current found with depth, it is important to determine the depth structure of the velocity found by the RAFOS floats.

To try to determine the depth structure of the RAFOS determined velocity, a series of test cases was examined. 


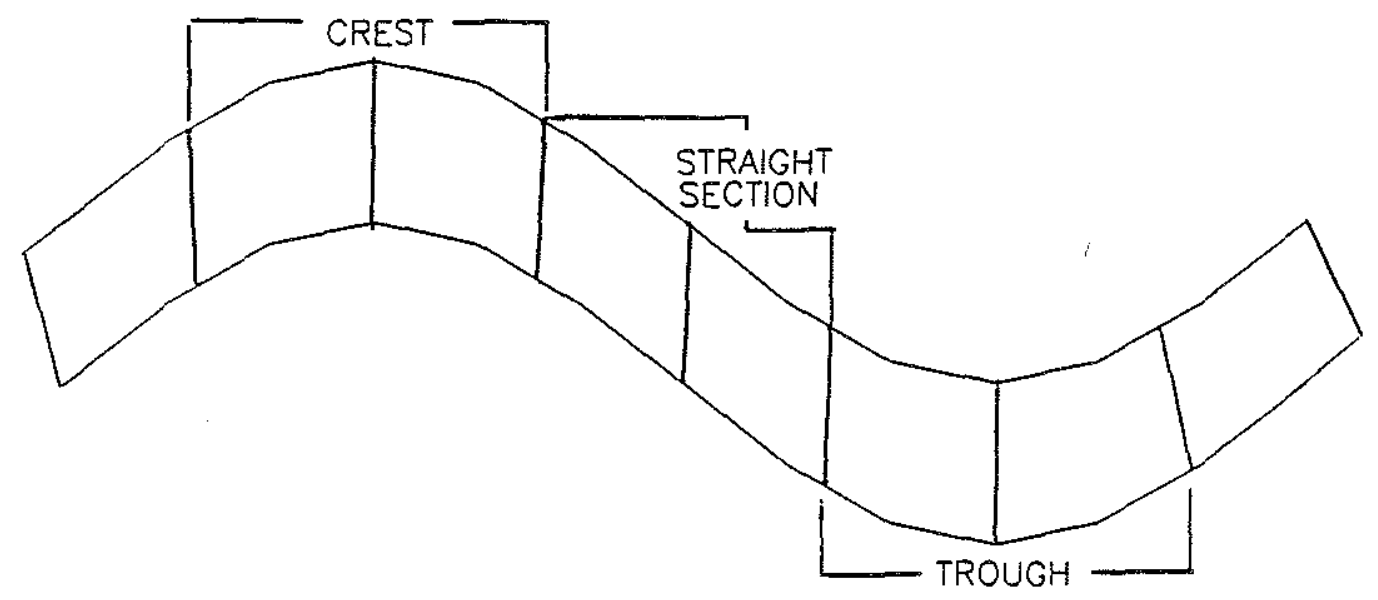

Figure 10

Sections of the Meander Pattern Used in Comparisons of Translational Hypothesis with RAFOS Data. 
From the RAFOS data it was apparent that the cross-stream velocity at lower depths within the stream would at least maintain the same direction within the meander pattern as the upper levels. The method used to look at the structure was to take the original data in the test cases chosen and subtract off a barotropic component associated with the measured RAFOS velocity (Test \#1) and a velocity that varied with depth (Test \#2). These tests were chosen since they are relatively simple, and also due to the sparsity of data.

The test cases were chosen from the plots such that the moorings were closest to the zero curvature line. This is the location of the highest cross-stream velocities detected using the RAFOS floats. Four moorings were found to be in this position. The cases chosen were:

$\begin{array}{llll}\text { Day } & 137 & \text { buoy } & \text { RH560X } \\ \text { Day } 149 & \text { buoy } & \text { RH557X } \\ \text { Day } 151 & \text { buoy } & \text { RH559X } \\ \text { Day } 249 & \text { buoy } & \text { RH558X }\end{array}$

The first three cases all disputed the hypothesis. The fourth case (Day 249 RH558X) supported the hypothesis.

\section{Test 1:}

For Test \#1 a RAFOS cross-stream velocity of $10 \mathrm{~cm} / \mathrm{s}$ was removed from the record aligned in a direction perpendicular to the North Wall data. The $10 \mathrm{~cm} / \mathrm{s}$ was taken out of both depths and the translational velocities were then recalculated. New plots were then made which showed the North Wall data, the mooring position (marked $\mathrm{x}$ ), the translation according to the translational hypothesis (marked 
R) (same as the earlier test plots), and the translation according to the translational hypothesis after the $10 \mathrm{~cm} / \mathrm{s}$ was removed from the records (marked B) (Fig. 11). From these plots it was determined whether or not the removal of the $10 \mathrm{~cm} / \mathrm{s}$ cross $-\mathrm{stream}$ component had improved or degraded the forecast. It was found that the removal aided in only one test case and also degraded one case (turning the one positive result to a negative result). This would lead to the likely rejection of a barotropic cross-stream RAFOS velocity.

Test 2 :

For test two the cross-stream velocity bias was decreased with depth according to the magnitude of the velocities measured (Eq. 2).

$$
\frac{\mid V_{1}}{\mid V_{u}} \frac{1}{\mid} 10 \mathrm{~cm} / \mathrm{s}=\left|V_{B}\right| \quad \text { Eq. } 2
$$

With: $\mid \begin{aligned} & \left|V_{u}\right|=\text { magnitude of the upper velocity } \\ & \left|V_{1}\right|=\text { magnitude of the lower velocity } \\ & \left|V_{B}\right|=\text { magnitude of the RAFOS velocity }\end{aligned}$

In this test it was found that the removal improved one test case and did not adversely affect any of the other examples. This suggests that there is some vertical structure to the RAFOS measured velocity. It is however impossible to determine the actual structure from the test cases available and it must be found through further in-situ experiments with the RAFOS floats. 


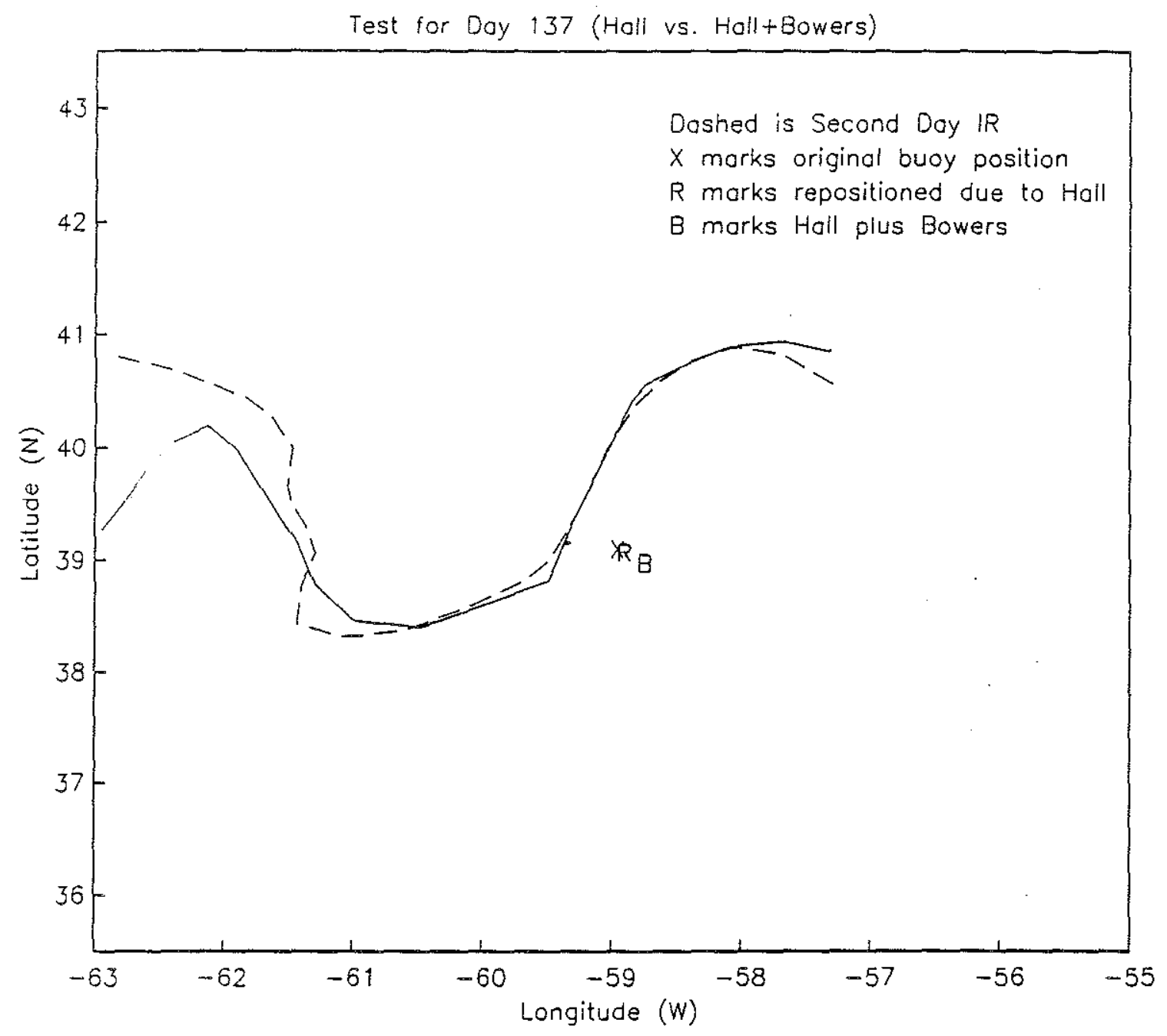

Figure 11

Plot of Test \#1 With Barotropic Velocity Removed According to RAFOS Measurements (B). Shows a Worsening from Original prediction ( $R$ ). 
Conclusions:

From the results shown certain conclusions can be drawn. The first is that the translational hypothesis cannot be used alone as a method for predicting translations of the Gulf stream surface thermal front. It is apparent however that the Hall decomposition does yield cross-stream velocities that are detected in the translations of the thermal front as seen in satellite data, but the agreement is observed only in the regions of the stream not associated with the recently measured RAFOS cross-stream velocities. The RAFOS measured velocities have some baroclinic structure, but this structure cannot be determined from the data available.

These conclusions lead to a view of the Gulf stream as having a solid structure which translates side to side and also contains additional cross sectional velocities associated with the meanders found in its path (Fig. 12). The cross sectional velocities seem to be associated with vertical velocities induced by the stretching of the water column compensating curvature-induced vorticity changes following the meanders, but this cannot be determined from the available data.

It is important that future work with the RAFOS floats include estimates of the depth variation in the cross-stream velocity. This would allow for a better understanding of the cross-stream velocity itself as well as aid in a better 


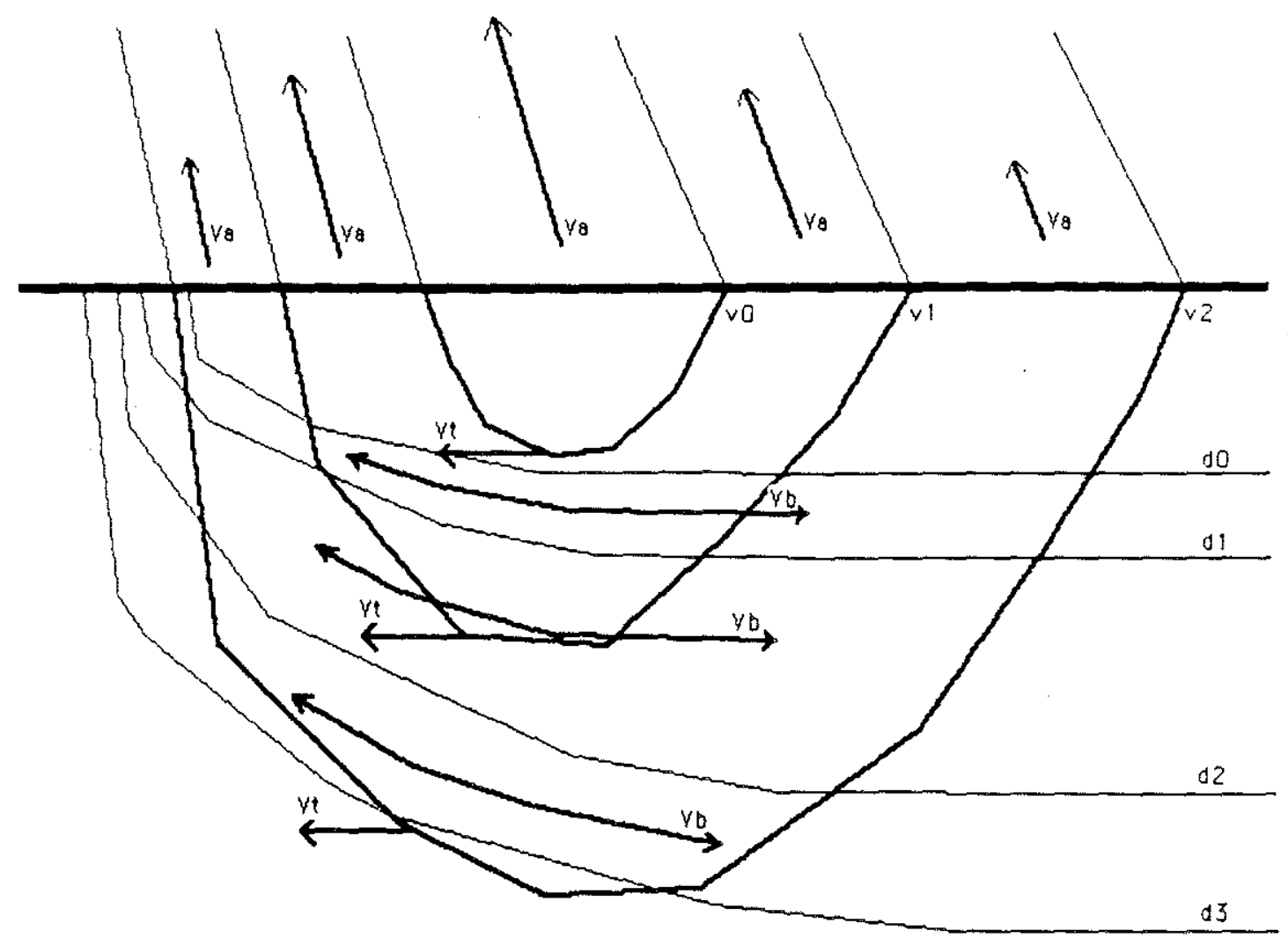

Figure 12

Diagram of Velocity and Density Contours Showing Both the Translational Velocity and the RAFOS

Measured Velocity.

Vax and $V t_{x}$ as before

$\mathrm{Vb}_{\mathrm{x}}=$ cross-stream flow along isopyncnals $\mathrm{d} x$ $\mathrm{Vb}_{0} \neq \mathrm{Vb}_{1} \neq \mathrm{Vb}_{2}$ 
determination of the manner in which the translational velocity, the RAFOS measured velocity, and possibly other cross-stream velocities are inter-connected. 


\section{Appendix A}

The moorings used are from three sources. In all cases the data used was only the data from the year 1983. A listing of the moorings is as follows:

Gulf Stream Statistical and Mapping Exp. Array: Mooring Name: Lat/Lon Location: Depths Used: RH557X

RH558X

RH560X

$39.50 \mathrm{~N}$

$59.00 \mathrm{~W}$ 445m.

$39.98 \mathrm{~N}$

$59.00 \mathrm{~W}$

$467 \mathrm{~m}$.

$39.02 \mathrm{~N}$

$59.02 \mathrm{~W}$

$495 \mathrm{~m}$.

$850 \mathrm{~m}$.

RH561X

$39.54 \mathrm{~N}$

$59.66 \mathrm{~W}$

$479 \mathrm{~m}$.

$1377 \mathrm{~m}$

$900 \mathrm{~m}$.

$884 \mathrm{~m}$.

GU1f STream Observational Experiment Mooring:

Mooring Name: Lat/Lon Location: Depths Used: GUSTO $37.50 \mathrm{~N} \quad 68.00 \mathrm{~W} \quad 700 \mathrm{~m}$. $700 \mathrm{~m}$.

AByssal Circulation Experiment Array: Mooring Name: Lat/Lon Location: Depths Used: ABCE780X $39.60 \mathrm{~N} 60.00 \mathrm{~W} \quad 513 \mathrm{M}$. $1009 \mathrm{~m}$. 


\section{Appendix B}

CONTOUR: CONTOUR is a public domain FORTRAN program written by Robert parker that draws contours from regularly gridded input.

PLOTXY: PLOTXY is a public domain FORTRAN program written by Robert Parker and Loren Shure that allows for the easy creation of plots of various data forms with appropriate annotations.

SDPS: $\quad$ Satellite Data Processing System created at the Woods Hole Oceanographic Institution. Developed by Chris Dunn and Mike Caruso for the processing and display of satellite data on the SUN Microsystems workstations.

ZGRID: ZGRID is a public domain FORTRAN program utilizing an algorithm created by David Anderson at the University of wisconsin to input unevenly gridded data and output evenly gridded data into appropriate sized arrays. 


\section{Appendix C}

The method used for comparing the translations observed in the plots and the translations predicted by the hypothesis was chosen for simplicity. The first step is to determine the point in the first days North Wall data that is the closest to the mooring being used (denoted by a box on the North Wall data in Fig. C1). The translation predicted by the current measurements at the mooring are then calculated by using the direction and distance by which the " $R$ " is separated from the original mooring position ("X"). The position located away from the box this distance, in the appropriate direction, is then determined (marked with a circle in Fig. (1). The plot is determined to support the hypothesis if a portion of the next dates (Day $x+2$ ) North Wall data passes within $10 \mathrm{~km}$. of this location. Ten kilometers is the accuracy of the North Wall data shown by Cornillon et. al. (1987).

In the case of Figure $c 1$, the southern-most mooring correctly predicted the translation shown in the North Wall data. The mooring directly above the southern-most mooring incorrectly predicted the translation, and the other two moorings would not be used due to their being located above the North Wall data during a portion of the time period in question.

Additional test plots are shown in Figures C2, C3, and C4. The plots also contain whether the moorings supported or 


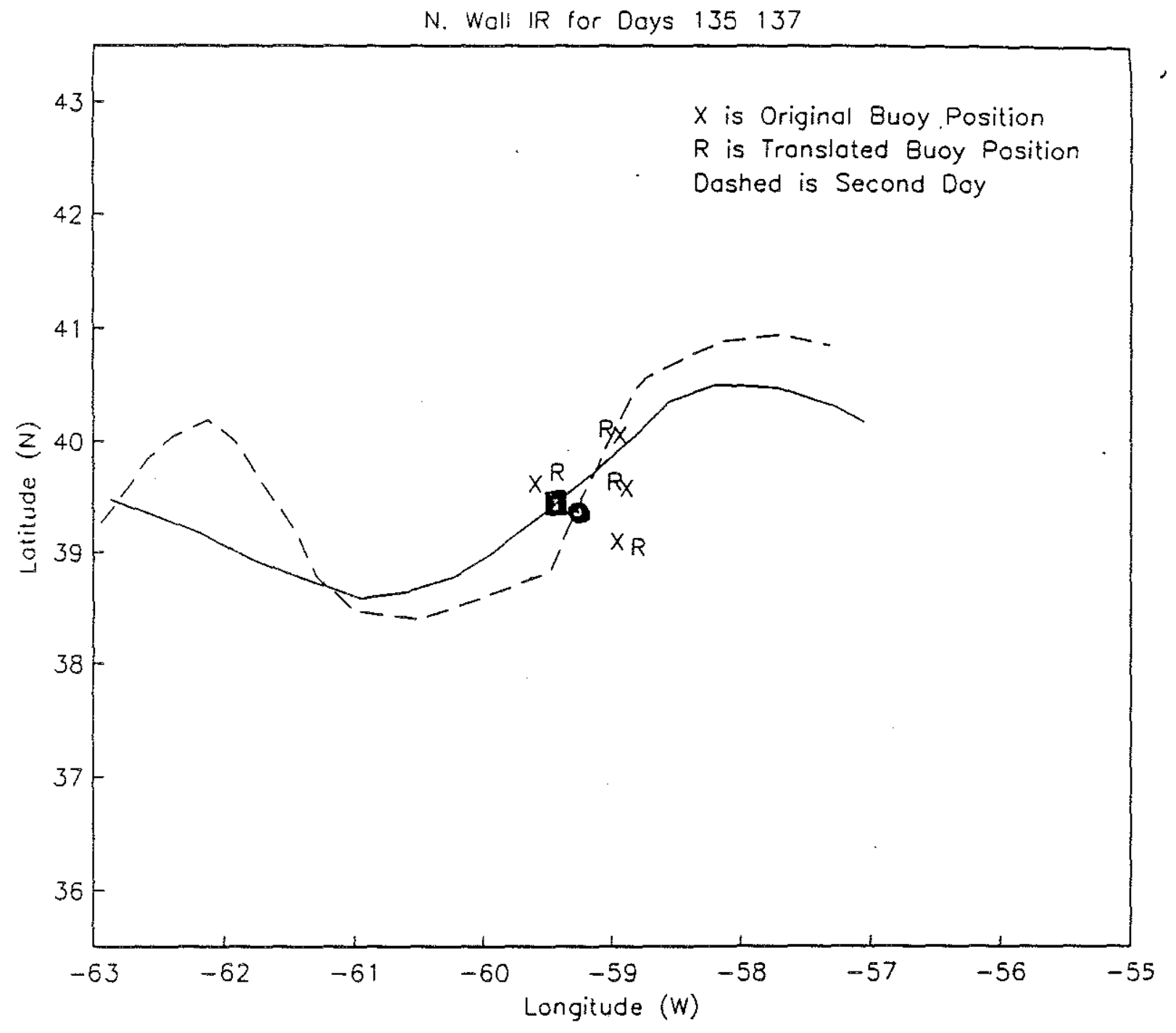

Figure C1

Test Plot Showing Scoring Method Used 
disputed the hypothesis. The numbering system used was to call the southern-most mooring number one, the mooring directly above it number two, the northern-most mooring number 3, and the final mooring four (Fig. C2, C3, and C4). A mooring marked "+" supported the hypothesis, "-" disputed the hypothesis, and a 0 denotes a mooring which could not be used in the analysis. 


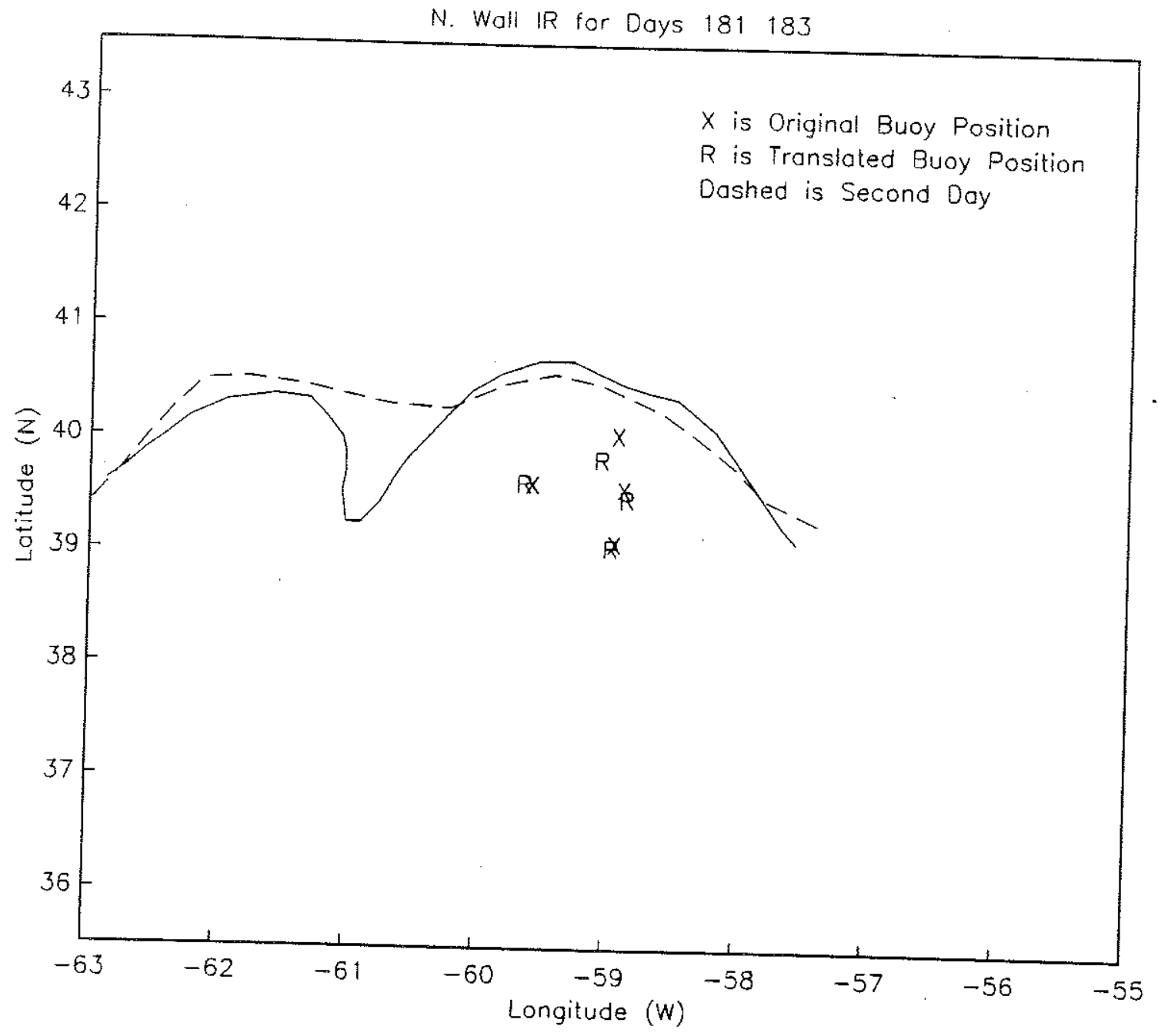

Figure C2

Mooring 1: +

Mooring 2: +

Mooring 3: -

Mooring 4: - 
N. Woll IR for Days 211213

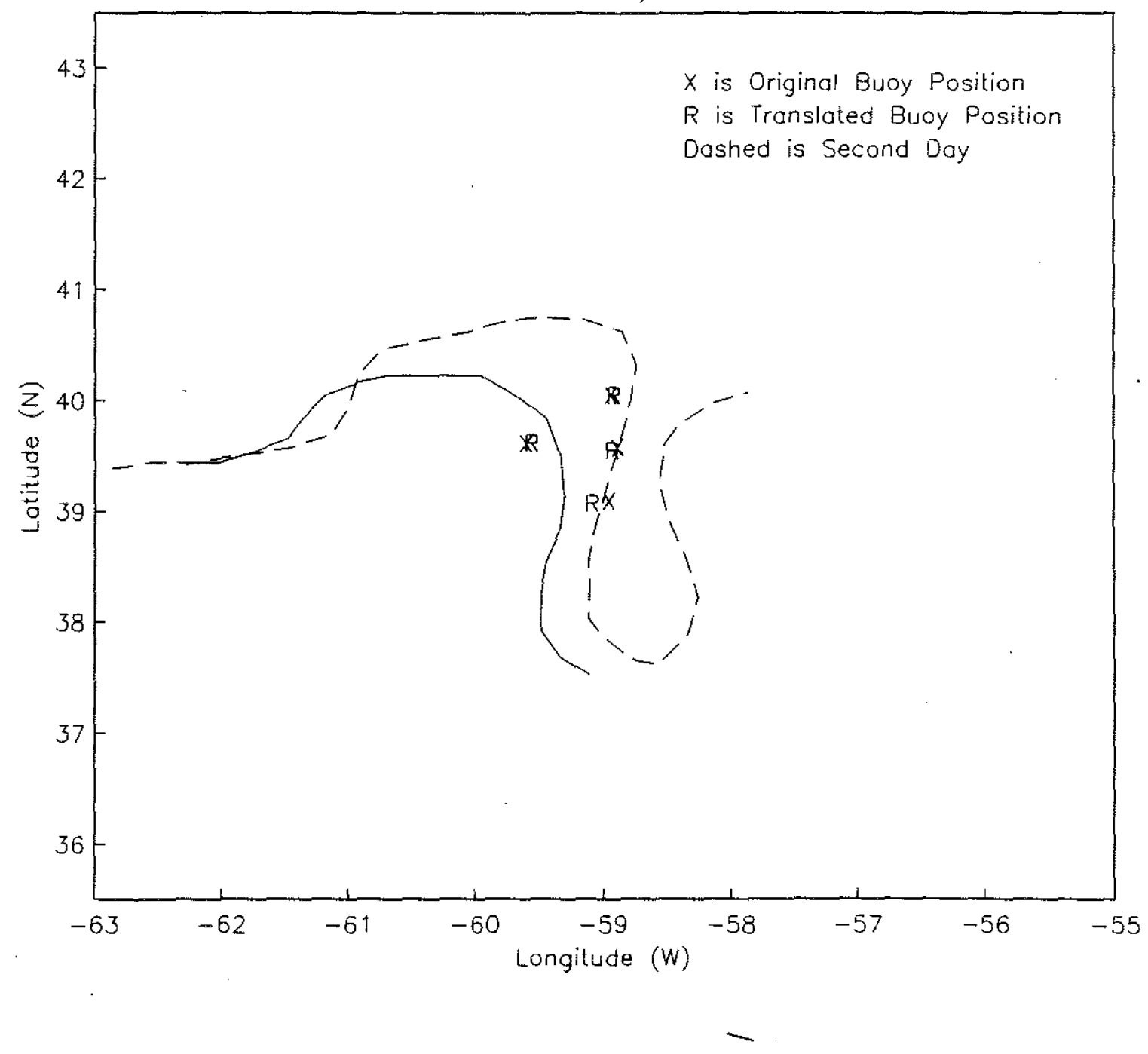

Figure $\mathrm{C3}$

Mooring 1: 0

Mooring 2: 0

Mooring 3: 0

Mooring 4: - 
N. Wall IR for Days 251253

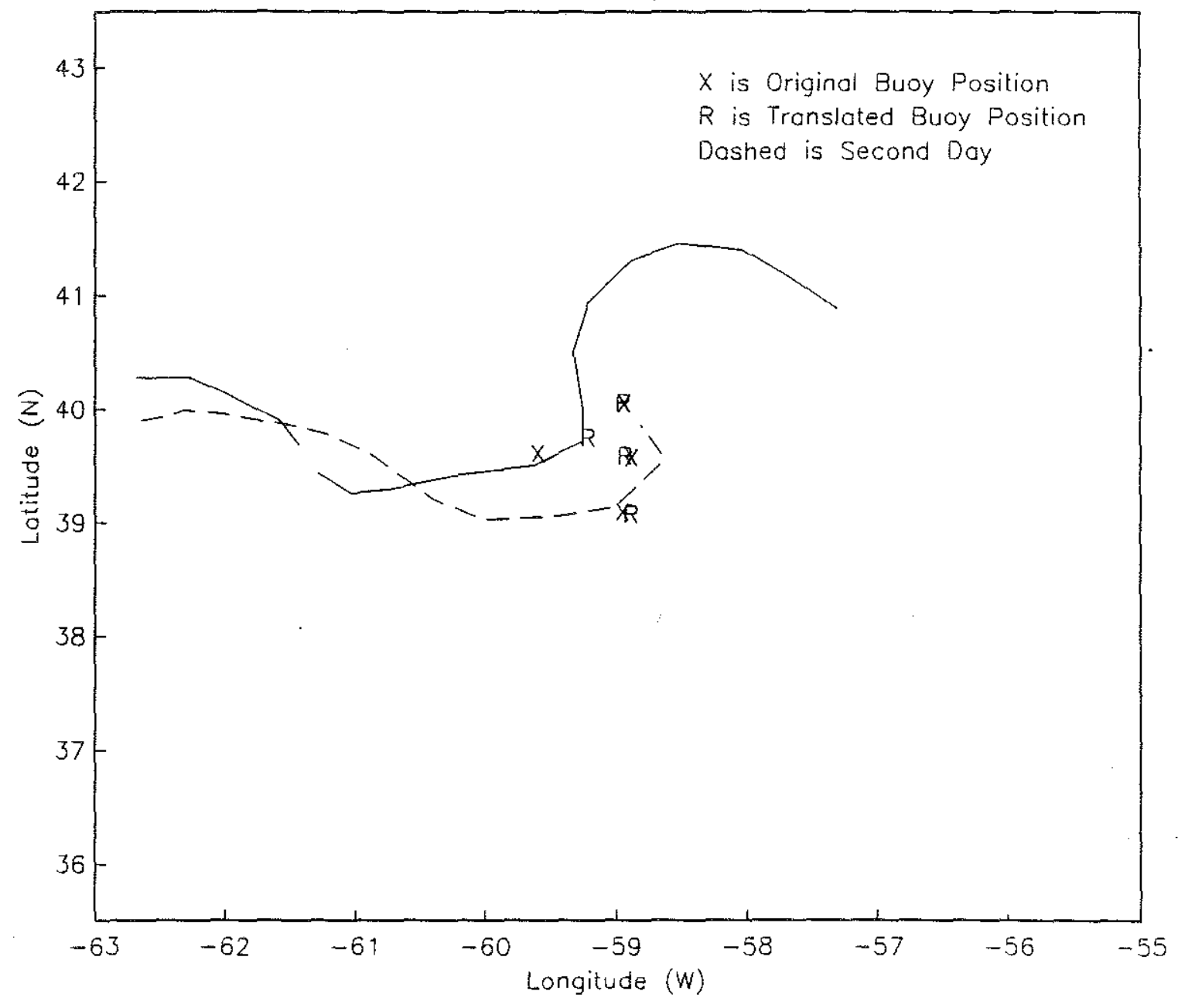

Figure C4

Mooring 1: -

Mooring 2: 0

Mooring 3: 0

Mooring 4: 0 


\section{Bibliography}

Atlantic Oceanographic Laboratory Cruise Report 84-012. CSS Hudson, Bedford Institute of Oceanography. 1984. Bower, A.. Isopyncnal Drifter studies in the Gulf stream. Doctoral Dissertation (Defense Copy), University of Rhode Island Graduate School of Oceanography. 1988. Cornilion, P.. The Effect of the New England Seamounts on Gulf Stream Meandering as Observed from Satelitite IR Imagery. Journal of Physical Oceanography, 16(2), p. 386-389. 1986 .

Cornillon, P., Gilman, C., Stramma, L., Brown, O., Evans, R., and Brown, J.. Processing arid Analysis of Large Volumes of Satellite-Derived Thermal Infrared Data. Journal of Geophysical Research, Vol. 92, No. C12, p. $12,993-13,002$. 1987 .

Fofonoff, N.. The Gulf stream system. Evolution of Physical Oceanography. Warren, B. and Wunsch, C., ed.s. The MIT Press, Cambridge, MA. p. 112-139. 1981.

Halkin, D. and Rossby, T.. The Structure and Transport of the Gulf Stream at $73 \mathrm{~W}$. . Journal of Physical Oceanography, 15, p. 1439-1452. 1985.

Hall, M.. Horizontal and Vertical structure of Velocity, Potential Vorticity, and Energy in the Gulf stream. Doctoral Dissertation. MIT/WHOI, WHOI-85-16. 1985. 
Hall, M.. Horizontal and Vertical of the Gulf stream Velocity Field at $68 \mathrm{~W}$. Journal of Physical Oceanography, 16, No. 11, p. 1814-1828. 1986A.

Hall, M.. Assessing the Energetics and Dynamics of the Gulf Stream at $68 \mathrm{~W}$ from Moored Current Measurements. Journal of Marine Research, 44, p. 423-443. 1986B

Hall, M. and Bryden, H.. Profiling the Gulf stream with a current Meter Mooring. Geophysical Research Letters, Vol. 12, No. 4, p. 203-206. 1985.

Hendry, R.. A Simple Model of Gulf stream Thermal structure with Application to the Analysis of Moored Measurements in the Presence of Mooring Motion. Journal of Atmospheric and Oceanic Technology, submitted.

Hogg, N., Pickart, R., Hendry, R., and Smethie, W.. The Northern Recirculation Gyre of the Gulf Stream. DeepSea Research, Vol. 33, No. 9, p. 1139-1165. 1986.

Johns, W. and Watts, D.. Gulf stream Meanders: Observations on the Deep Currents. Journal of Geophysical Research, Vol. 90, No. C3, p. 4819-4832. 1985.

Levy, E. and Tarbell, S.. Moored Current Meter and Temperature-Pressure Recorder Measurements from the Western North Atlantic (H.E.B.B.L.E. and A.B.C. Experiments 1983-1984) Vol. XXXIX. Tech. Report. WHOI-86-14. 1986. Rossby, T., Bower, A., and Shaw, P.. Particle Pathways in the Gulf stream. Bulletin of the American Meteorological society, Vol. 66, No. 9, p. 1106-1110. 1985. 
$R / V$ Hakon Mosby. University of Rhode Island Graduate School of Oceanography, University of Bergen Institute of Geophysics Report no. 65. Joint cruise report. 1986.

Shaw, P. and Rossby, H.. Towards a Lagrangian Description of the Gulf Stream. Journal of Physical Oceanography. Vol. 14, p. 528-540. 1984 .

Stommel, H.. The Gulf Stream. University of California Press Berkeley and Los Angeles. 1958.

Wylie, C, and Barrett, L.. Advanced Engineering Mathematics, Fifth Edition. McGraw-Hill Book Company, New York. 1982. 